\title{
Epilepsy in Prisons: A Diagnostic Survey
}

\author{
JOHN GUNN,* M.B., CH.B., D.P.M.; GEORGE FENTON, $\dagger$ M.B., M.R.C.P., D.P.M.
}

\begin{abstract}
Cummary : A previous study has suggested that epilepsy $S$ is commoner in prisons than in the general population. We devised a standard definition of "epilepsy" and then interviewed a representative sample of the "epileptics" in prisons: The results confirmed the initial conclusion, and showed the point prevalence of epilepsy in prison and Borstals to be at least 7·1/1,000 men.
\end{abstract}

\section{Introduction}

In 1966 one of us (J. G.) conducted a census of the epileptic population being received into prisons and Borstals in England and Wales during one month and a point prevalence census of epileptic residents in such institutions on one day. These surveys, which have been reported elsewhere (Gunn, 1969), indicated that about $8 \cdot 8 / 1,000$ men received into prison were designated epileptic or doubtfully epileptic by the Prison Medical Department, and that the point prevalence of epileptics in prisons and Borstals was also about $8 \cdot 7 / 1,000$ men. When compared with a survey conducted by the College of General Practitioners (1960) these figures are higher than those of the general population, the high prevalence being particularly pronounced among the younger epileptics.

Nevertheless, a bias introduced by a tendency for the prison medical staff to use less rigid diagnostic criteria than those applied during the epidemiological prevalence studies, and therefore to overdiagnose epilepsy, must be excluded before it can be assumed that prisoners are more prone to suffer from epilepsy than their more law-abiding compatriots. The following investigation was undertaken in an attempt to clarify this problem.

\section{Methods}

One of us (J.G.) visited the 20 penal establishments in England and Wales that had reported a population of four or more epileptics in the point prevalence census and 10 of those establishments which received only an occasional epileptic. On arrival at each institution the responsible prison doctor furnished a list of all the inmates designated "epileptic" or "doubtfully epileptic" at that point in time. This list constituted the spot sample for that particular prison or Borstal institution, and the men chosen were interviewed during the course of the next day or so.

A control group from the same prison to allow medicosocial and criminological comparisons, which will be reported elsewhere (Gunn, 1970), was also examined. The controls were prisoners considered by the prison medical staff not to have epilepsy. They were obtained by inspecting the numerical index file of each prison and Borstal and selecting those subjects whose cards were next (alternately before and after) to that of each proband. In these files each prisoner's name is recorded in chronological order of reception to that institution. Thus was provided a control sample which matched the probands for sex, institution, and duration of stay at that institution. Subsequent inquiry (Gunn, 1969b) had demonstrated that the two groups were also matched with regard to age, length of sentence, and nature of offence.

* Research Worker, Institute of Psychiatry, Camberwell, London S.E.5, and Honorary Senior Registrar, Maudsley Hospital.

and Hon S.E, † Senior Lecturer, Institute of Psychiatry, Caudsley Hospital.
Each man was interviewed at length. A standard medical, psychiatric, and forensic history was taken and he was questioned about the possible occurrence of " fits," " blackouts," and "turns," any account of such phenomena being recorded verbatim. Further information was obtained from previous hospital records, and descriptions of any attacks witnessed by the prison staff were added later. A number of the men had had E.E.G. examinations in the past, and the reports on these were noted. Many had not, and for them, whenever possible, the prison doctors would arrange a routine E.E.G. to be carried out, so that eventually we had some electroencephalographic information about $84 \%$ of the cases.

One hundred and ninety-two probands and a similar number of controls constituted the two samples initially.

At the end of the survey all the data from each subject relevant to the diagnosis of epilepsy-that is, patients' accounts and eye-witnesses' descriptions of the seizures, stated age of onset of the attacks, previous history of significant C.N.S. damage, personal history, alcoholism, or family history of epilepsy-were extracted and recorded on a sheet separate from the other information collected. These sheets were then examined and rated independently by us, one of whom (J.G.) had interviewed the patient, thus bringing to the rating procedure (described below) his recollection of the interview and examination, while the other (G. F.) had no data apart from the rating sheet. This procedure was regarded as the best compromise between a clinical evaluation which could be biased by other, perhaps irrelevant, data obtained during the interview and a blind rating by independent observers who might be misled by the manner in which the clinical details were presented on the manuscript.

\section{Definition}

In defining our own criteria for epilepsy we were concerned to try to obtain a circumscribed description which would be as objective as possible and facilitate our rating procedure, at the same time providing one with which few epileptologists would disagree, so that interstudy comparison might be possible at a later date.

Many would agree with Symonds (1955) that very little qualification need be added to Jackson's 1890 criterion: "[epilepsy is] the name for occasional, sudden, excessive, rapid and local discharge of grey matter." It is remarkable how this early statement has stood the tests of time and advancing knowledge, but, as Hill (1963) pointed out, "epilepsy is not a disease but may be a symptom of many diseases," and therefore subclassifications are necessary for a meaningful diagnosis.

Most modern definitions agree with Jackson by implying something about disordered brain function from the observed clinical phenomena. For example, the College of General Practitioners in 1960 defined the epileptic attacks as "all attacks primarily cerebral in origin in which there is a disturbance of movement, feeling, behaviour, or consciousness-that is, excluding fainting, aural vertigo and psychologically determined attacks." Lennox and Lennox (1960) went further than this and defined epilepsy as:

" a disorder of the brain expressed as paroxysmal cerebral dysrhythms. The dysrhythmia, if symptomatic, is associated with seizures composed of one or more of the following recurrent and involuntary phenomena: (1) Loss or derangement of consciousness 
or remembrance (amnesia); (2) excess or loss of muscle tone and movement; (3) alteration of sensation, including hallucinations of special senses; (4) disturbance of the autonomic nervous system with resulting vegetative and visceral phenomena of various sorts; (5) other psychic manifestations, abnormal thought-processes or moods."

Such a definition, while providing guidance about clinical symptomatology, leaves undefined the term "paroxysmal cerebral dysrhythmia" and would seem to include patients with E.E.G. changes in the absence of clinical seizures. Hill (1963) makes his definition entirely clinical: "The more or less sudden occasion of motor, visceral, psychical, or behavioural symptoms -events which in any given patient are likely to recur throughout his life as episodic phenomena, at times related to known precipitating circumstances but not necessarily so." But he goes on to explain that "the episodic phenomena, defined by the symptoms, can only be understood in terms of excitability in some part or parts of the nervous system."

Many classifications of these phenomena have been used, sometimes from a clinical point of view and sometimes from the electroencephalographic. Perhaps the most widely used system, by reason of its attempt to closely relate E.E.G. and clinical phenomena, has come from the so-called "McGill studies," which based their classification on location of a presumed epileptic focus in the brain (Jasper and Kershman, 1949).

A very comprehensive classification which attempted to embrace clinical, electroencephalographic, anatomical, and aetiological factors was presented by a Commission on Terminology of the International Federation of Societies for Electroencephalography and Clinical Neurophysiology in 1964 (Gastaut et al., 1964). For the purposes of the present study, however, which depended largely on clinical evaluation, we were obliged to formulate a more clinically orientated phenomenological definition and classification: Epilepsy is said to occur in someone who has had three or more epileptic attacks, either during the past two years or, if before that time, is still on anticonvulsant medication; and An Epileptic Attack is an intermittent, stereotyped disturbance of behaviour, emotion, motor or sensory function, which on clinical grounds is judged to be the result of pathological cortical neuronal discharge.

The attacks were then divided into four mutually exclusive categories on the basis of presumed site of onset of the seizure discharge. These were defined as follows:

(1) Subcortical.-Attacks which occur in an individual who gives no account of initial phenomena ${ }^{1}$ other than generalized myoclonus and for whom there is no clinical or E.E.G. evidence of acquired cerebral pathology, but who exhibits bilaterally synchronous spike and wave discharges in the E.E.G.

(2) Focal Cortical-Temporal.-Attacks which occur in an individual who clearly describes $(a)$ sudden stereotyped initial phenomena which he recognizes as foreign to his usual self and which can be classified under one of the following categories: sensations or hallucinations of smell or taste; complex auditory or visual hallucinations, perceptual illusions concerning the self, the environment, or time; epigastric sensations; affective changes, mainly fear or elation; and/or (b) unequivocal E.E.G. evidence of focal spike or sharp wave discharges in one or both anterior or mid-temporal regions.

(3) Focal Cortical-Other.-These are attacks which begin with progressive, consistently lateralized motor or sensory phenomena other than those described above and/or accompanied by dysphasia (initial or post-ictal), and/or forced thinking, and/or simple visual hallucinations, and/or a sudden field defect ; or they are generalized convulsions occurring in patients with unequivocal evidence of previous cortical damage.

(4) Unrateable.-Any epileptic attack as defined in the primary definition which has none of the distinguishing features of the other secondary definitions. (This group mainly includes episodes of unconsciousness without initial phenomena or without clear evidence

1 "Initial phenomena" are the beginnings of an epileptic attack, whether sensory, motor, or psychical, and whether or not followed by a major gen:ralized seizure (see Penfield and Kristiansen, 1951). of cortical damage, or those initiated by such non-specific symptoms as giddiness, vertigo, faintness, or headache.)

\section{Ratings}

Each patient was placed in one of the following three categories-“epileptic," "doubtfully epileptic," and "nonepileptic"-the raters displaying a conscious tendency to err on the cautious side and down-grading the category to doubtful or non-epileptic if there was any doubt regarding diagnosis.

Using this system we had 162 cases out of the 192 in which complete agreement was reached initially ( $84.4 \%$ agreement). At a meeting between the raters the 30 remaining cases were discussed and eventually $100 \%$ agreement was reached. The prison medical officers rated $75 \%$ of the sample as definitely epileptic (though in the original residents' census (Gunn, 1969a) they had rated only $70 \%$ as such), whereas with fuller information and a standard definition we were able to include $82.3 \%$ as definitely epileptic (Table I).

TABLE I.-Prison Medical Officers' Ratings Compared with the Survey

\begin{tabular}{|c|c|c|c|c|c|}
\hline \multirow{2}{*}{\multicolumn{2}{|c|}{$\begin{array}{c}\text { Prison } \\
\text { M.O. } \\
\text { Ratings }\end{array}$}} & \multicolumn{4}{|c|}{ Survey Ratings } \\
\hline & & Epileptic & Doubtful & Non-epileptic & Total \\
\hline $\begin{array}{l}\text { Epileptic } \\
\text { Doubtful }\end{array}$ & $\because$. & $\begin{array}{r}126 \\
32\end{array}$ & $\begin{array}{l}9 \\
7\end{array}$ & $\begin{array}{l}9 \\
9\end{array}$ & $\begin{array}{r}144(75 \%) \\
48(25 \%)\end{array}$ \\
\hline Total & $\ldots$ & $158(82 \%)$ & $16(8 \%)$ & $18(9 \%)$ & $192(100 \%)$ \\
\hline
\end{tabular}

The control cases were submitted to a slightly different procedure. All the men who gave a history of "fits," "attacks," " epilepsy," "funny turns," etc., or were subsequently discovered to have such a history, were noted, and the cases from this selected group were each discussed in detail between the raters. Here the objectives were directed less towards an accurate diagnosis and more towards the identification of possible epileptics. Three men were rated as definitely epileptic, five men as "recovered" epileptics, and one as " not known" because of lack of data.

The diagnostic subgroups of the probands were similarly discussed until full agreement about category was reached. The numbers and proportions for each are shown in Table II. Unfortunately, it is not possible to make a valid comparison between the proportions obtained in this survey with any general population figures, for, as Gastaut (1953) has pointed out, the estimates of the prevalence of temporal lobe epilepsy vary widely between 30 and $80 \%$ of cases. (Juul-Jensen's (1964) important survey disagreed with even this wide estimate, for he reported that only $24 \%$ of his cases were temporal lobe epileptics.) One striking feature of the present series, however, is the low number of patients examined who did not suffer from grand-mal attacks (only three cases)-a finding in contrast to the $18 \%$ of such cases discovered by Gudmundsson (1966) in Iceland recently in his total epilepsy survey.

\begin{tabular}{|c|c|c|c|c|}
\hline & & & No. & Percentage \\
\hline $\begin{array}{l}\text { Subcortical } \\
\text { Temporal } \\
\text { Other focal } \\
\text { Unrateable }\end{array}$ & $\begin{array}{l}\ldots \\
\cdots \\
\cdots\end{array}$ & $\begin{array}{l}\ldots \\
\cdots \\
\cdots\end{array}$ & $\begin{array}{l}23 \\
48 \\
31 \\
56\end{array}$ & $\begin{array}{r}14.6 \\
30.4 \\
19.6 \\
35.4\end{array}$ \\
\hline Total & $\ldots$ & .. & 158 & 100 \\
\hline
\end{tabular}

\section{Modification of Census Result}

These results enabled us to rescale the original residents' census (Gunn, 1969). A simple proportional method was used for this. The 190 epileptic cases and the 81 doubtfully epileptic cases of the December 1967 census were transformed in the ratios apparent from Table I-that is, the new estimate for epileptics is $190 \times \frac{126}{1+4}+81 \times \frac{32}{12}=220$. A similar estimate has been made for the "doubtful epileptics" and the 
"non-epileptics," and the rescaled figures are set out in Table III, where it will be seen that even then the prevalence does not fall below $7 \cdot 1$ epileptics per 1,000 men, a figure well above the $3 \cdot 74 / 1,000$ found in the general population of Iceland (Gudmundsson, 1966) or the $4.45 / 1,000$ found in general practices of England and Wales (College of General Practitioners, 1960). The prison prevalence is significantly higher than that found in the general practice survey $\left(\chi^{2}=36.4,1 \mathrm{df}, \mathrm{P}<0.0005\right)$.

TABLE III

\begin{tabular}{|c|c|c|c|}
\hline & & $\begin{array}{l}\text { December } 1967 \text { Residents' } \\
\text { Census (Gunn, 1969) }\end{array}$ & $\begin{array}{l}\text { Rescaled Census } \\
\text { Figures }\end{array}$ \\
\hline $\begin{array}{l}\text { Epileptics } \\
\text { Doubtful epileptics } \\
\text { Non-epileptics ... }\end{array}$ & $\because$ & $\begin{array}{r}190 \\
81 \\
\end{array}$ & $\begin{array}{c}220(7 \cdot 1 / 1,000) \\
24 \\
(27)\end{array}$ \\
\hline Total .. & $\ldots$ & $271(8 \cdot 7 / 1,000)$ & 244 \\
\hline
\end{tabular}

The rates per 1,000 are calculated using the total prison population of night 13 December 1967 , which was 30,993 men.

There are, however, several reasons for presuming this figure to be an underestimate for the prison population. The prison medical staff involved in the survey pointed out, almost without exception, that they are cautious and conservative in their diagnosis of epilepsy, dropping the label or putting the man into the "doubtful" category whenever objective data are missing. An unexpectedly low proportion of the probands were without grand-mal seizures, suggesting that some of those with less dramatic forms of epilepsy may not have been detected. Our discovery of three previously undetected epileptics in the control population of 192 is consistent with these observations.

In addition it should be remembered that not all institutionalized epileptic offenders will be found in prisons. Some will be sent to mental hospitals and a few will find their way to the special hospitals. A crude estimate of the numbers of epileptics in the special hospitals of England and Wales (Broadmoor, Rampton, and Moss Side) can be made by reference to Price and Whatmore (1967). In a survey conducted for other purposes they estimated that $12 \%$ of the inmates of Carstairs State Mental Hospital (the Scottish special hospital that takes all the security risk cases from Scotland, both mentally ill and mentally subnormal) were epileptic. If this proportion is similar for the special hospitals of England and Wales then in September 1967, where there were 2,162 patients in Broadmoor, Rampton, and Moss Side (Department for Health and Social Security, 1968) there would have been approximately 259 epileptics in those hospitals. A recent check made by Tennant (1969) revealed that in June 1969 there were in fact in these hospitals 270 male patients regarded as epileptic on account of current seizures and necessity for anticonvulsants.

\section{Discussion}

From these results we must inevitably conclude that prisons contain an increased prevalence of epilepsy compared with the general population and, by implication, that epileptics have a higher probability of finding themselves in prison than other members of the community. This observation contrasts markedly with that of Juul-Jensen (1964), who found that only $5.5 \%$ of his epileptic patients had committed criminal actsmuch the same prevalence as in the general population of Denmark. Alström (1950) had also recorded a similar finding from his epilepsy clinic in Sweden. As Juul-Jensen points out, however, both these surveys were confined to hospital and clinic patients and therefore excluded those who were institutionalized, and he might have added that those who were too disorganized to come into contact with the services provided were also excluded.

Pond and Bidwell (1960) found that only about half of the epileptics attending general practitioners attended a hospital department, and in the first census of prisoner epileptics conducted in the present survey (Gunn, 1970) we found that on reception $45 \%$ of the men claimed never to have attended a hospital outside of prison, $73 \%$ said that they had never had even a routine E.E.G., and $11 \%$ stated that they had never taken anticonvulsants. When an extensive survey was undertaken by Gudmundsson (1966) in Iceland, in which he tried to contact all the epileptics on the island, the relation between epilepsy and legal trouble was demonstrated. $\mathrm{He}$ found that $8.3 \%$ of epileptic men and $0.6 \%$ of epileptic women aged 16 years and over had a police record, a figure for the men which is three times the equivalent estimate for the general population.

A number of factors may be involved in the pathogenesis of the antisocial behaviour in our sample of epileptic prisoners. The finding that at least half had symptomatic epilepsy is consistent with the view that the underlying epileptogenic lesion, because of either its site or its extent, may cause disturbances of personality and behaviour. Social influences, however, may be equally or more important. The social isolation and rejection that is the lot of so many epileptics may provoke antisocial behaviour as a reaction. It is possible that many of our subjects come from deprived and disturbed environments in which one might expect the level of parental, social, and medical care to be low, with a consequent higher incidence of obstetric abnormalities and an increased risk of infective and pathogenic insults during childhood. The child brought up in this type of environment may therefore be exposed to a greater risk of acquiring brain damage and subsequent epilepsy. Finally, disorganized impulsive personalities, prone to get into social difficulty, may also sustain cerebral injury as a result of their behaviour-for example, by driving a motor cycle carelessly.

Clearly these explanations are not mutually exclusive, nor will any one of them account for all the epileptics seen in prison, but they are tentative hypotheses which warrant further examination by both criminologists and medical practitioners. It is hoped that detailed analysis of the medical and social data collected during this survey will throw some light on this problem.

We gratefully acknowledge the encouragement given by Professor T. C. N. Gibbens, who directed this inquiry, the generous financial support of the Medical Research Council, and the co-operation of the Prison Medical Department, especially the help provided by Dr. D. O. Topp with the census and some of the interviews. The Home Office Statistical Branch conducted a special retrospective survey of part of the 1966 criminal statistics especially for this survey, and Miss B. Kinsley gave statistical advice.

The Home Office granted permission to publish this paper, but it should be emphasized that the opinions expressed belong to us and do not necessarily imply official agreement.

\section{REFERENCES}

Alström, C. H. (1950). Acta Psychiatrica et Neurologica Scandinavica, Suppl. No. 63.

College of General Practitioners (1960). British Medical fournal, 2, 416 Gastaut, H. (1953). Epilepsia, 2, 59.

Gastaut, H., et al. (1964). Epilepsia, 5, 297.

Gudmundsson, G. (1966). Acta Neurologica Scandinavica, 43, Suppl No. 25.

Gunn, J. C. (1969). Proceedings of the Royal Society of Medicine, 62,

Gunn, J. C. (1970). M.D. Thesis to be presented to the University of

Hill, D. (1963). In Electroencephalography, edited by D. Hill and G. Parr, p. 250. London, Macdonald.

Jasper, H. H., and Kershman, J. (1949). Electroencephalography and Clinical Neurophysiology, Suppl. No. 2, p. 123. Juul-Jensen, P. (1964). Acta Neurologica Scandinavica, 40, Suppl. No. 5. orders. Boston, Little Brown.

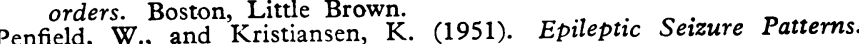
Springfield, Thomas.

Pond, D. A., and Bidwell, B. H. (1960). Epilepsia, 1, 285. Price, W. H., and Whatmore, P. B. (1967). British Medical fournal, 1,
533.

Department for Health and Social Security (1968). The Special Hos pitals and the State Hospital, Cmnd. 3709. London, H.M.S.O.

Symonds, C. (1955). British Medical fournal, 1, 1235.

Tennant, G. (1969). Personal communication. 